\title{
Preparation and Rheological Properties of Attapulgite Gel for Aqueous Suspensions
}

\author{
Tao Zhang ${ }^{1, a}$, Tianqi Li $i^{1, b}$, Yuechao Liu, ${ }^{1, c}$, Yang $\mathrm{Li}^{1, \mathrm{~d}}$, Gaowei Guo ${ }^{1, \mathrm{e}}$, \\ Jingcheng Cui ${ }^{1, f}$ and Fengshan Zhou ${ }^{1,} g^{*}$
}

${ }^{1}$ Beijing Key Laboratory of Materials Utilization of Nonmetallic Minerals and Solid Wastes, National Laboratory of Mineral Materials, School of Materials Science and Technology, China University of Geosciences (Beijing), 100083

a457872221@qq.com, b2052618032@qq.com, csanerk@163.com, d348681695@qq.com, e465946799@qq.com, ${ }^{\mathrm{f}} 842587243 @ q q . c o m,{ }^{\mathrm{g}}$ zhoufs@cugb.edu.cn

*The corresponding author

Keywords: Attapulgite gel; Aqueous suspension; Rheological Property; Drilling fluid; Anaerobic fermentation slurry

\begin{abstract}
A new modified attapulgite gel was prepared as a rheological modifier in liquid fertilizer produced by biogas anaerobic fermentation slurry and in oil well drilling fluids. Magnesium oxide showed a great contribution to apparent viscosity and plastic viscosity of attapulgite aqueous suspensions, the main reason perhaps was the inversion of attapulgite rods configuration because of the electrostatic attractive interactions between magnesium oxide particles with positive charges and attapulgite rods with positive charges. This higher viscosity will provide better cuttings carrying capability during drilling fluid circulation especial at low velocity. Dispersants adjusted the electrolyte level of the dispersions, influenced the surface charge of the clay mineral particles, broken up the aggregated configuration of attapulgite gel, and then improved the yield point of the attapulgite suspension. The yield point was declined with increasing dosage of dispersants in present work. Sodium polyacrylate exhibited a superior effect to other dispersants for the rheological behavior of attapulgite gel. Cationic polyacrylamide was an effective additive which affected the gel strength and the gel structure shift on time-dependent at low content. The optimized rheological modifier was obtained in present work which contained 3.5\% magnesium oxide, $0.75 \%$ sodium polyacrylate, $0.5 \%$ alpha sodium naphthol sulfonate, and $0.05 \%$ cationic polyacrylamide in the attapulgite clay.
\end{abstract}

\section{Introduction}

Biogas engineering as a new type of clean energy is speeding up its development in China. A large number of anaerobic fermentation slurry produced by large and medium-sized biogas project were difficult to deal with. To prepare the slurry to liquid fertilizer will be a kind of high added value utilization direction. Owing to the current situation of oil shortage and the drilling of complex strata in oilfield, the selection and preparation of drilling fluids with good functions had become more and more important. Clays and clay minerals, such as bentonite, sepiolite, and attapulgite were widely used in water-based drilling fluids [1]. Asbestos, also used as an effective drilling mud additive, with its cylinder-shaped and fibrous structure can form a scaffolding configuration, which can increase fluid viscosity and improved cuttings carrying capability. Moreover, asbestos gel in drilling fluid suspension has a good thixotropic performance [1]. Countermanding the advantages of the mineral, asbestos fibers can be deposited in the lungs, and cause fatal cancers, which harm to the health of drilling workers. Based on occupational safety considerations, the use of asbestos additive is gradually being done away with [2].

Attapulgite, with general formula $(\mathrm{Mg}, \mathrm{Al})_{2} \mathrm{Si}_{4} \mathrm{O}_{10}(\mathrm{OH}) \cdot 4\left(\mathrm{H}_{2} \mathrm{O}\right)$ or $\mathrm{Mg}\left(\mathrm{Al}_{0.5-1} \mathrm{Fe}_{0-0.5}\right) \mathrm{Si}_{4} \mathrm{O}_{10}(\mathrm{OH})$. $4 \mathrm{H}_{2} \mathrm{O}$ while some aluminum ions were replaced by iron ion at equal values, is a chain-layer magnesium-aluminum silicate typical of natural fibrous clay mineral. Attapulgite has a wide range of industrial applications because of its special absorptive, colloidal, rheological, and catalytic 
properties, such as in drilling mud, petrochemical, building materials, chemistry, papermaking, medicine, agriculture, food, environmental protection, and so on. Alexander and Arieh [3] first suggested the possible use of Sacalum (Yucatan) attapulgite as a drilling mud. As a kind of effective drilling fluid additive, attapulgite has the advantage over other clay minerals (such as bentonite) in being less sensitive to salts and temperature, i.e. the desired rheological properties remain constant even at high-electrolyte concentrations, which is why attapulgite can be widely used in both marine and salt formation drilling.

When considering the natural fibrous structure of attapulgite, previous studies have focused mainly on attapulgite nanorods, which can be well dispersed in suspension affecting the discoloration or absorption ability of attapulgite [4]. Several researchers have recognized that the adsorption performance of attapulgite depends on the huge specific surface area that occurs due to the needle-like nanorods forming micro-channel or nanostructure tunnels. Fan et al. [5] modified attapulgite with ammonium citrate tribasic (ACT) and used ACT-attapulgite as an adsorbent to remove $\mathrm{Ni}^{2+}$ from aqueous solutions; they reported that ACT-attapulgite could be used in wastewater treatment because of its negative surface charge and large surface areas. Zhang et al. [6] prepared modified attapulgite with magnesium and aluminum salts for adsorption of fluoride ions from water. The natural attapulgite surface was negatively charged. The approach of a fluoride anion would suffer repulsion from the strong anionic groups in attapulgite. The cationic metals modification improved the adsorption capacity of attapulgite due to more anion exchange between fluoride ion and hydroxyl group of attapulgite.

The rheology of clay minerals in dispersion, especially bentonite is now well known: Mahto and Sharma [7] conducted a study of a water-based oil well drilling fluid; Dur'an et al. [8] studied the relationship between rheological and electro kinetic properties of sodium montmorillonite dispersion; and Change et al. [9] investigated the effects of $\mathrm{pH}$, ionic strength, and temperature on the rheology and stability of aqueous clay mineral dispersion. However, no detailed analysis has been done on the similarity of fiber microstructure between asbestos and attapulgite and on the thixotropy of modified attapulgite gel as a thixotropic modifier for drilling fluid suspension.

Dispersant agents and polyelectrolyte were also used to modify the surface properties of attapulgite. The rheological and thixotropic properties of modified attapulgite were also investigated. Because of the need to improve occupational safety, another aim of the work in this paper was to investigate practical ways in the preparation of modified attapulgite gel to substitute asbestos in drilling applications, especially as a thixotropic modifier .

\section{Experimental Detail}

Materials. Asbestos and bentonite samples were obtained from the Shengli oilfield (Shandong province, China). Attapulgite sample with purity greater than $95 \%$ was received from the Mingguang mining site (Anhui province, China). The average length of the attapulgite rods is around $1 \mu \mathrm{m}$, and the average aspect ratio is about 20. The chemical compositions of the clay mineral are $64.89 \% \mathrm{SiO}_{2}, 12.95 \% \mathrm{Al}_{2} \mathrm{O}_{3}, 1.26 \% \mathrm{TiO}_{2}, 8.19 \% \mathrm{Fe}_{2} \mathrm{O}_{3}, 0.16 \% \mathrm{FeO}, 9.11 \% \mathrm{MgO}, 1.48 \%$ $\mathrm{CaO}, 0.07 \% \mathrm{Na}_{2} \mathrm{O}, 1.33 \% \mathrm{~K}_{2} \mathrm{O}, 0.43 \% \mathrm{P}_{2} \mathrm{O}_{5}$, and $0.02 \% \mathrm{SO}_{3}$. According to the compositions, the formula of attapulgite in present work was described with the $\left(\mathrm{Mg}_{0.81} \mathrm{Al}_{0.73} \mathrm{Fe}^{3+}{ }_{0.36} \mathrm{Ca}_{0.09} \mathrm{Ti}_{0.06}\right)\left(\mathrm{Si}_{3.83} \mathrm{Al}_{0.17}\right) \mathrm{O}_{10}(\mathrm{OH}) \cdot 4 \mathrm{H}_{2} \mathrm{O}$. The cationic exchange capacity (CEC) was $49.8 \mathrm{meq} / 100 \mathrm{~g}$ and specific surface area was $462.0 \mathrm{~m}^{2} / \mathrm{g}$. The cationic polyacrylamide (CPAM) used in the experiment has a molecular weight of 8000000 and was purchased from Mitsubishi Chemical Holdings Co. (Japan). Sodium polyacrylate (PAA-Na) was synthesized in the laboratory using the neutralization method, and had a viscosity-average molecular weight of 9 000-10 000. Based on this molecular weight range, the PAA-Na was suitable used as a dispersant. Industrial dispersant alpha sodium naphthol sulfonate (FDN) sample was obtained from the Shengli oilfield. Other analytically pure chemicals used in the experiments were sodium tripolyphosphate (STPP), sodium pyrophosphate (SPP), sodium hexametaphosphate (SHMP), and hexadecyl trimethyl ammonium bromide (CTAB).

Instruments. The modified attapulgite was filtrated by SHB-III water circulation Pumps (180W; 
Xi'an, Taikang Biotechnology Co., Ltd.), and dried by 101-3A electric blast drying Oven $\left(300^{\circ} \mathrm{C}\right.$; Shanghai, Rolling-gen Equipment Co., Ltd.). The gelation of samples dispersion prepared after being stirred by GJ-2S digital display high-speed Agitator (180W, 4000-11000 rpm; Qingdao), Rheological and Filter loss measurements of gels were conducted by ZNN-D6A six-speed rotary Viscometer (speed: 3. 6. 100. 200. 300. $600 \mathrm{rpm}$, viscosity range: 0-300 mPa.s; Qingdao) and ZNS-2A medium pressure dehydration Filter tester (Filter loss area: $45.6 \mathrm{~cm}^{2}$, Working pressure: $0.69 \mathrm{MPa}$; Qingdao), the three kinds of instruments were manufactured by Qingdao Haitongda Special Instrument Co., Ltd. The rpm is the abbreviation for revolutions per minute

Chemical Additives Pressing. Certain amounts of additives were added into $6.4 \%$ attapulgite dispersions by weight. The dosage of chemical additives (\%) in the figures is the ratio of mass between chemicals and attapulgite. After correlative data were converted, the concentrations of the chemical additives to the attapulgite dispersion were as follows: $\mathrm{MgO}$ and CTAB: $0.64,1.92,3.2$ g/L; STPP and SPP: 0.32, 0.48, 0.64 g/L; PAA-Na: 0.24, 0.48, 0.96, 1.92 g/L; SHMP: 0.32, 0.64, $1.92 \mathrm{~g} / \mathrm{L} ;$ FDN: 0.64, 0.96, 1.28, 1.6, $1.92 \mathrm{~g} / \mathrm{L}$; and CPAM: 0.0128, 0.0192, 0.0256, 0.32, 0.64, 0.96 $\mathrm{g} / \mathrm{L}$.

The dispersions were stirred mechanically $(8000 \mathrm{rpm})$ for $20 \mathrm{~min}$ at room temperature and hydration conducted for $24 \mathrm{~h}$. The reaction time was $24 \mathrm{~h}$. The term of hydration was an ageing process of water penetrating the interlayer spaces and concomitant adsorption with the clay swelling and colloidization.

Rheological Parameters Measurement. Darley and George [1] concluded the common composition and properties of drilling and completion fluids. According to the American Petroleum Institute (API) and Recommended Practice [10], the parameters of the attapulgite gel in the drilling fluid suspension samples were prepared and measured under the specification and standard procedures [11]. The viscosity and gel strength of the modified gels were tested by a rotating viscometer $\left(\mathrm{ZNN}_{\mathrm{N}} \mathrm{D}_{6} \mathrm{~S}\right)$. The hydrated gels underwent mechanical stirring with $8000 \mathrm{rpm}$ for a further $20 \mathrm{~min}$. This preparation step before measuring the viscosity was to make the dispersion even and flowing. And then the viscosity was measured at different shear rates (different stirring velocity).

Rheological Theory. It is generally accepted that drilling fluids can be typified by the Bingham-plastic model [1]. The Bingham-plastic model of flow differs most notably from a Newtonian fluid by the presence of a yield stress. A Bingham-plastic fluid will not flow until the applied shear exceeds a minimum value that is known as the yield stress. The Bingham-plastic model relates shear stress and shear rate by the equation $[1,12]$ :

$$
\tau=\tau 0+\mu 0 \gamma
$$

where $\tau$ is the shear stress, $\tau_{0}$ the yield point, $\mu_{0}$ the plastic viscosity, and $\gamma$ the shear rate.

According to Bingham-plastic model, the rheological parameters, including AV (apparent viscosity), PV (plastic viscosity), YP(yield point), and RYP (ratio of yield and plastic viscosity) were calculated with the dial readings of $300 \mathrm{rpm}$ and $600 \mathrm{rpm}$ using the following formula's according to the American Petroleum Institute (API) recommended practice of standard procedures [10].

$$
\begin{aligned}
& \mathrm{AV}=0.50600 \quad(\mathrm{mPa} . \mathrm{s}) \\
& \mathrm{PV}=0600-\theta 300 \quad(\mathrm{mPa} . \mathrm{s}) \\
& \mathrm{YP}=0.511(\theta 300-\mathrm{PV}) \quad(\mathrm{Pa}) \\
& \mathrm{RYP}=\mathrm{YP} / \mathrm{PV} \quad(\mathrm{Pa} / \mathrm{mPa} . \mathrm{s})
\end{aligned}
$$

Where $\theta_{600}$ is the dial reading of rotating viscometer at $600 \mathrm{rpm}$, and $\theta_{300}$ is the dial reading of rotating viscometer at $300 \mathrm{rmp}$. 


$$
\begin{aligned}
& \tau_{10 \mathrm{~s}}=0.511 \theta_{3, \mathrm{I}} \\
& \tau 10 \mathrm{~min}=0.511 \theta 3, \mathrm{~F}
\end{aligned}
$$

$\Delta \tau=\tau 10 \mathrm{~min}-\tau 10 \mathrm{~s}$

Where $\tau_{10 \mathrm{~s}}$ is the gel strength after $10 \mathrm{~s}$ suspension not under shear, $\theta_{3, \mathrm{I}}$ is the initial dial reading of rotating viscometer at $3 \mathrm{rpm}$ after $10 \mathrm{~s}$ suspension. The $\tau_{10 \mathrm{~min}}$ is the gel strength after $10 \mathrm{~min}$ suspension not under shear, $\theta_{3, \mathrm{~F}}$ is the final dial reading of rotating viscometer at $3 \mathrm{rpm}$ after $10 \mathrm{~min}$ suspension. $\Delta \tau$ is the difference between $\tau_{10 \min }$ and $\tau_{10 \mathrm{~s}}$ that means the strength of shear thixotropy or shear thinning of the drilling fluid at the low shear rate.

Microscopic Examination. The morphology of the attapulgite and modified attapulgite with additives was observed in a Quanta 200FEG environmental scanning electron microscope (SEM). Three raw minerals were made to powder samples, which were dried from dilute $0.2 \%$ dispersions before the SEM examination. The modified attapulgite gel samples were also dried out from the same concentration before SEM measurement.

\section{Results and Discussion}

Falode et al. [12] carried out rheological and filtration tests on bentonite samples obtained from Pindiga Formation in the Borno Basin of Nigeria, and their results explained that the viscosity of mud was a function of three rheological parameters i.e. plastic viscosity, yield point, and gel strength.

Attapulgite, unlike bentonite, would be formed gel structures in salt water and was used in brine drilling fluids while drilling formations contaminated with salt [1]. Attapulgite particles could be considered as charged particles with zones of + and - charges. It was the bonding of these alternating charges that allowed them to form gel suspensions in salt and fresh water. The special lattice gel structures of attapulgite aqueous suspensions formed by hydrogen bonds could be suspend the large dense cuttings, and required relatively low power for mud pump during drilling fluid circulation $[13,14]$.

Evaluation of three raw minerals as materials of drilling fluid. The experimental results for the three raw minerals (Table 1) revealed that asbestos had a larger PV, compared with attapulgite and bentonite, and at the meantime, the gel strength was appropriately smaller. When considering application to the drilling field, this performance of asbestos gel for drilling fluid suspension not only has better cuttings carrying capacity, but also avoids pump blockage and surge pressure due to quick configuration reforming and appropriate gel strength value.

Table 1 Some rheological and thixotropic parameters of the three clays studied (clay gel in $6.4 \mathrm{wt} \%$ suspension)

\begin{tabular}{ccccccccc}
\hline Clay & AV & PV & YP & $\tau_{10 s}$ & $\tau_{10 \min }$ & $\Delta \tau$ & YP/PV & FL $(\mathrm{mL})$ \\
\hline Attapulgite & 19.5 & 4 & 15.5 & 8.5 & 15 & 6.5 & 3.88 & 124 \\
Bentonite & 17.5 & 5.5 & 12 & 9.5 & 18.25 & 8.75 & 2.18 & 7.5 \\
Asbestos & 17.5 & 14 & 3.5 & 3 & 2.5 & -0.5 & 0.25 & 32 \\
\hline
\end{tabular}

PV is a property of plastic fluid, and does not vary with changes in velocity gradient. The PV reflects the internal frictions of suspended particles, and liquid phase and between these when the damage and recovery of the mud network structure in the laminar flow reaches dynamic balancing. The high dispersion of suspended particles can increase internal frictions and contribute to elevation of PV. The low PV values illustrated that the attapulgite particles were not well dispersed. 
On the other hand, closely stacked clay mineral particles or over-flocculation enlarge chemical force and result in a raise in YP, which is related to the flow resistance due to electrochemical force, especially the attractive force in the drilling fluid system.

The SEM micrograph measurement of the fibrous morphology of bare attapulgite (Fig. 1) also showed that the attapulgite rods were in poor dispersion and aggregated or over flocculated.

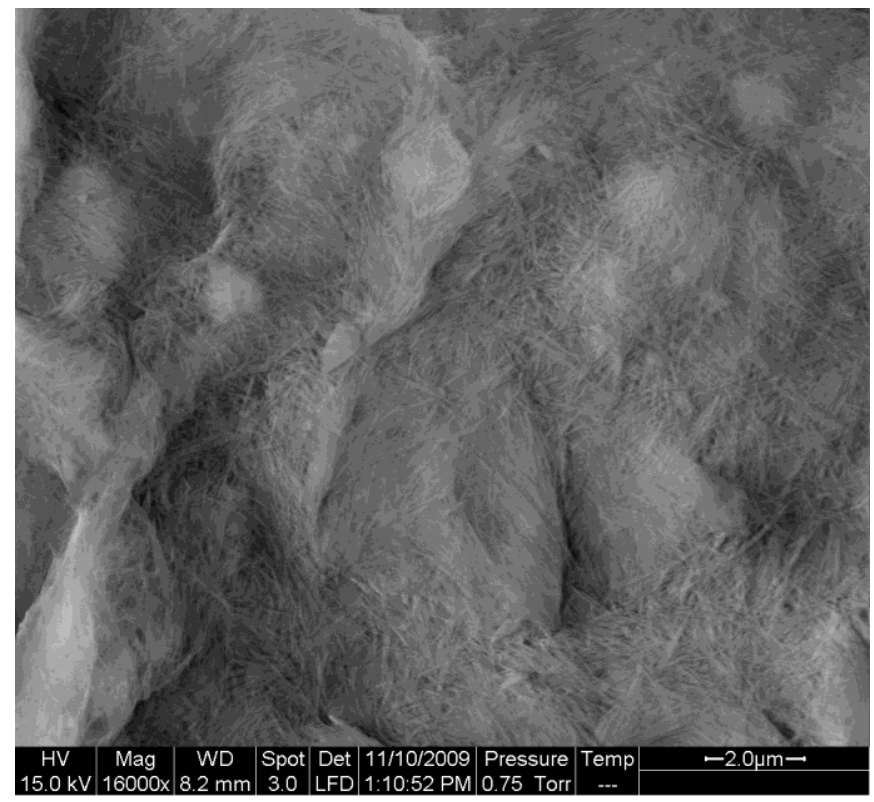

Figure 1. Scanning electron microscope photograph of unmodified attapulgite

The experimental measurements of raw minerals (Table 1) also disclosed that the YP/PV of attapulgite was larger than that of asbestos, and, according to the rheological requirement for oil-well drilling fluids [1], this ratio should be in the range of $0.25-3.0$ or $0.75-1.0$, better in 0.36-0.48. A suitable YP/PV guarantees effective cutting removal for hole cleaning and prevents the borehole wall from being washed away by turbulence to keep hole stability.

Furthermore, experimental measurements of rheological and thixotropic parameters (Table 1) revealed the difference of $\Delta \tau$ among the three minerals.

Measurements of rheological and thixotropic parameters of bentonite (Table 1) revealed bentonite had smaller PV and larger YP than asbestos, which resulted in larger YP/PV. In addition, $\Delta \tau$ of bentonite was the largest among the three raw materials. As previously stated, with these properties, bentonite might be low dispersion, not effective suspension and cutting removal, besides turbulence, pump blockage, and surge pressure.

Under shear force, the structure of a drilling fluid is destroyed and the viscosity declines. The recovery of the structure of a drilling fluid brings an increase in viscosity when shear stops. Yin $e t$ al. [15] noticed an obvious shear thinning behavior of attapulgite nanoparticles in fluids at high shear rate, indicating that all curves were located in the non-Newtonian region. What's more, the low content of rod-like clay minerals was easy to diffuse in the solution and the rods oriented in the flow direction under shear force.

For many of the complex non-Newtonian fluids, thixotropy is a typical representation of a time-dependent effect of viscosity or viscoelasticity. Thixotropy expresses the internal structure variation with shear and time. The $\tau$ increases with the growth of deposition time. So $\Delta \tau$ was used to characterize thixotropy in this study.

In drilling applications, gel strength and thixotropic properties of a gel have direct and fundamental impacts on cutting suspension and the circulation resistance of pump restarting. In order to suspend cutting instead of sinking, a gel needs to have such a fast and strong thixotropy that the beginning $\tau$ point can reach an appropriate level rapidly as soon as circulation stops. Also, the final $\tau$ can't be too large because, in that case, the pump pressure will be too high when pumping is restarted, which may cause excessive surge pressure or even lost circulation. So a fast 
and moderately intensive thixotropic property of a gel is needed in drilling to suspend well cuttings and to resume circulating mud at low pump pressure.

Effects of Chemical Additives on Apparent and Plastic Viscosity. The experimental measurements of samples with chemical additives (Fig. 2 and Fig. 3) exhibited that the sample added $\mathrm{MgO}$ showed an increased viscosity value at lower $\mathrm{MgO}$ content. This higher viscosity value exhibited better cuttings carrying capability.

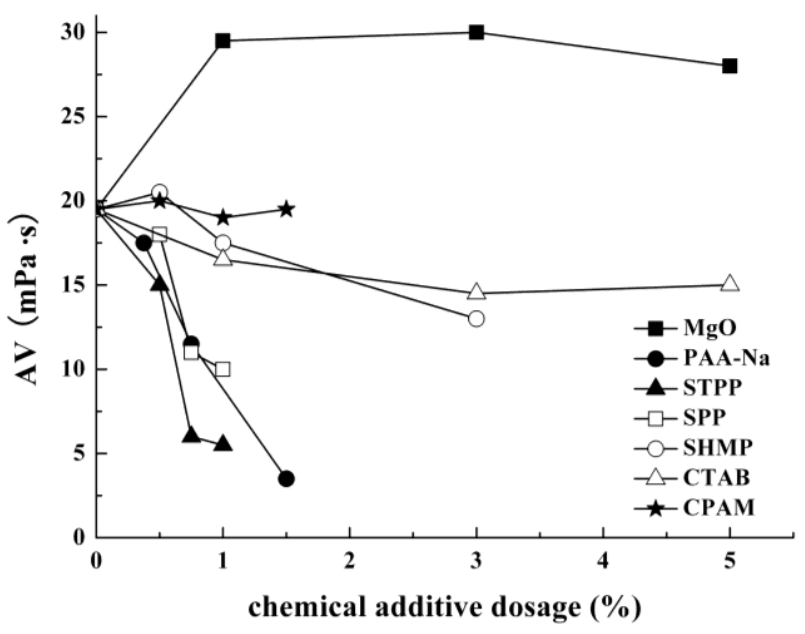

Figure 2. Effect of chemical additives on the apparent viscosity (AV) of attapulgite gel

PAA-Na means sodium polyacrylate; STPP means sodium tripolyphosphate; SPP means sodium pyrophosphate; SHMP means sodium hexametaphosphate; CTAB means hexadecyl trimethyl ammonium bromide; CPAM means cationic polyacrylamide. Units of $\%$ here defined a $w t \%$, means the ratio of mass between chemicals and attapulgite.

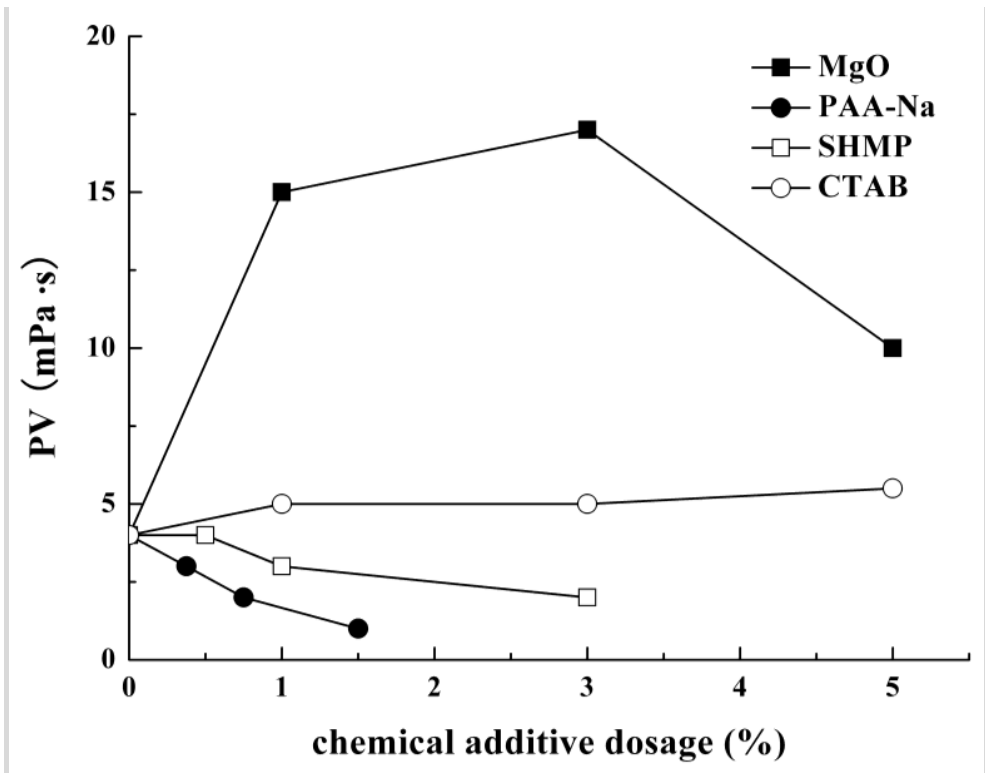

Figure 3. Effect of chemical additives on the plastic viscosity (PV) attapulgite gel

PAA-Na means sodium polyacrylate; SHMP means sodium hexametaphosphate; CTAB means hexadecyl trimethyl ammonium bromide; Units of $\%$ here defined a $w t \%$, means the ratio of mass between chemicals and attapulgite.

When $\mathrm{MgO}$ particles were added to water, the reaction happened as follows [16, 17]:

$$
\mathrm{MgO}+\mathrm{H} 2 \mathrm{O}=\mathrm{Mg}(\mathrm{OH}) 2 \rightleftharpoons \mathrm{Mg} 2++2 \mathrm{OH}-
$$


The cationic exchange ability of $\mathrm{Mg}^{2+}$ is better than $\mathrm{Na}^{+}$. The $\mathrm{Mg}^{2+}$ entered into the channels of clay mineral particles and caused shrinkage of the electrical double layer. The shrinkage of the electrical double layer easily formed face-face aggregation. At the same time, the absorbed $\mathrm{Mg}^{2+}$ bridged edge and face, forming edge-edge and edge-face flocculation.

As already stated above, the PV reflects the internal friction of suspended particles, the liquid phase and their interface. Flocculation reinforces the suspension network structure with expression of an increase on viscosity.

SEM micrographs of the attapulgite with $\mathrm{Mg}(\mathrm{OH})_{2}$ and $\mathrm{MgO}$ (Fig. 4) revealed that the attapulgite had a fibrous morphology and that $\mathrm{Mg}(\mathrm{OH})_{2}$ and $\mathrm{MgO}$ particles with positive charge dispersed in the attapulgite scaffolding structure with negative charge. The electrostatic attractive interaction also reinforced the attapulgite structure, confirming the increase in viscosity.

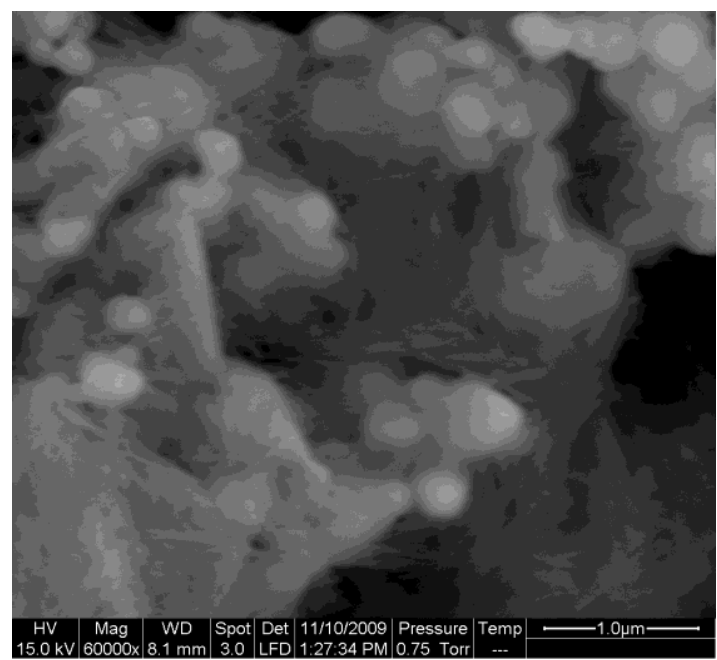

(a)

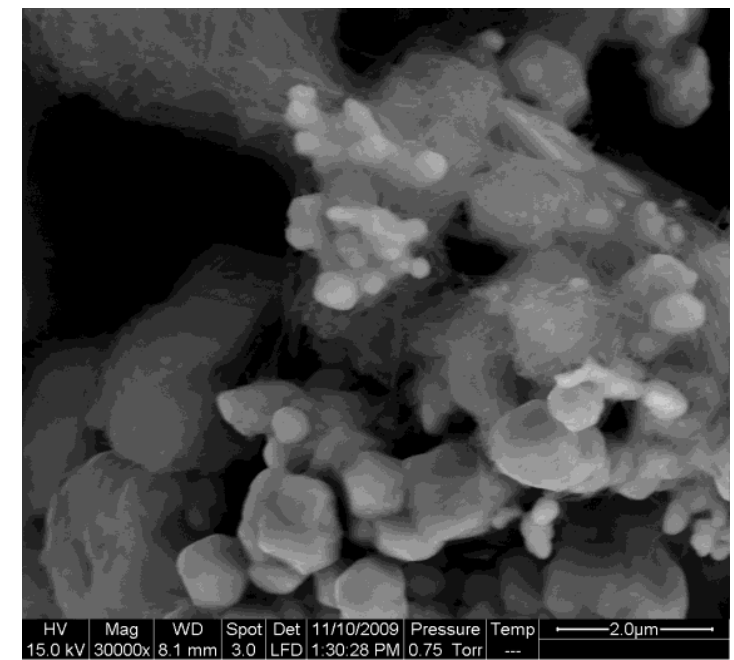

(b)

Figure 4. Scanning electron microscope photograph of attapulgite with $\operatorname{Mg}(\mathrm{OH})_{2}$ and $\operatorname{MgO}$ (a: $\mathrm{MgO}$ and $\mathrm{Mg}(\mathrm{OH})_{2}$ colloid aggregates $(1 \mu \mathrm{m})$; b: local picture of a, $\mathrm{MgO}$ and $\mathrm{Mg}(\mathrm{OH})_{2}$ colloids $(0.2 \mu \mathrm{m}))$

On the other hand, the value of the sample added CPAM did not vary much with increasing CPAM content. What's more, other samples such as those with added PAA-Na showed a decreased AV with increasing content.

Effects of Chemical Additives on Yield Point. The surface chemistry of a clay mineral has great influence on the rheological behavior with dispersion. Cao et al. [18] investigated electrochemical properties of $\mathrm{Na}$-attapulgite. The surface charge showed dependency on $\mathrm{pH}$ and electrolyte concentration. Zhou et al. [19] examined rheological properties controlled by chemical and physical methods. In that study, repulsion was observed with dispersions of polyelectrolyte-coated surfaces of particles. Kristen and Jonas [20] conducted a interfacial chemistry and rheological behavior study of talc suspensions. Zeta-potential measurements showed a dependence on $\mathrm{pH}$, talc solid content, and type and concentration of ions.

The experimental measurements of YP (Fig. 5) showed that adding PAA-Na, SHMP, and CTAB brought about dropping YP of gel. As dispersant agents, these anion electrolytes absorbed edge surface of clay mineral particles and caused a reversal of $\varepsilon$. As a result, the former positive-edge surface-negative-face surface flocculation was destroyed by that repulsion because of the same negative charge. As was said earlier, YP is connected with electrochemical force and represents the strength of gel structure while in flow. The YP value is crucial for cutting removal. However, a too high YP sets off over-fluctuation of the pressure and wash wall seriously, which are harmful for the stability of the borehole and may cause bore sloughing. The modified gel used in this study had a low-flow resistance and better rheology as a result of chemical repulsion and the effect of steric 
hindrance for the long chains of dispersant agents.

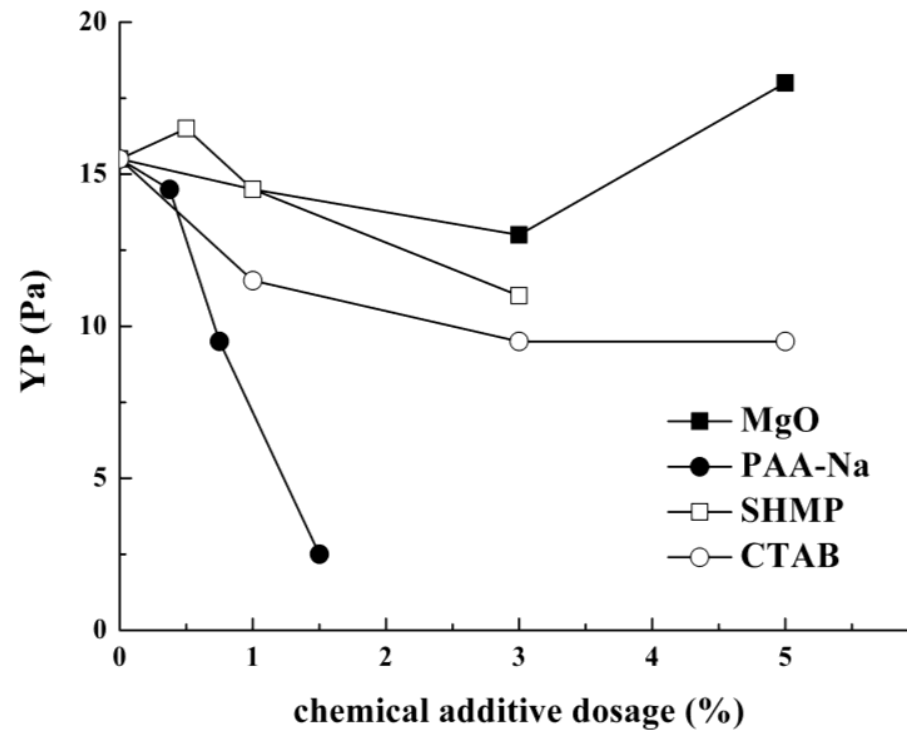

Figure 5. Effect of chemical additives on the yield point (YP) of attapulgite gel

PAA-Na means sodium polyacrylate; SHMP means sodium hexametaphosphate; CTAB means hexadecyl trimethyl ammonium bromide; Units of $\%$ here defined a wt $\%$, means the ratio of mass between chemicals and attapulgite.

The morphology of attapulgite with added dispersant (Fig. 6(a) ) showed that the dispersant agents were absorbed onto the attapulgite rods. Some surfaces of the attapulgite particles were fully coated by the dispersant agents. Comparison of the SEM measurements of attapulgite morphology (Fig. 1 and Fig. 6(b) ) indicated that the former over-fluctuation configuration was broken up and the clay mineral particles dispersed well. The flexible interface layer consisting of coating dispersant-agent chains effectively prevented the attapulgite rods from growing into clusters and reuniting. Experimental measurement of clay mineral dispersion (Fig. 6(c)) showed that in the lower part of the suspension, not like dispersed fibrous attapulgite rods could be suspended steadily, and the impurity mineral settled under gravity and separated from the attapulgite. Consequently, the dispersant agents had the purifying effect of removing impurities [21, 22].

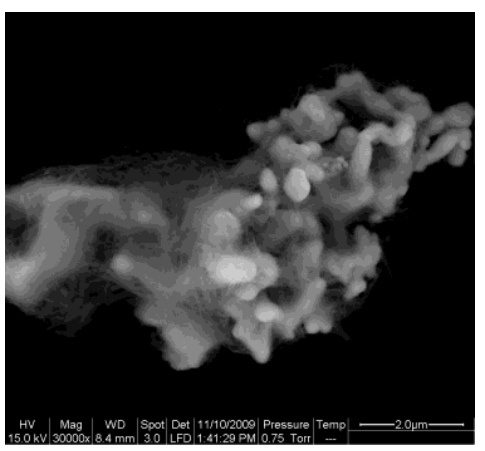

(a)

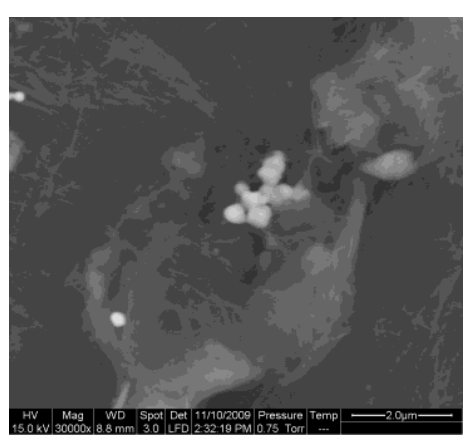

(b)

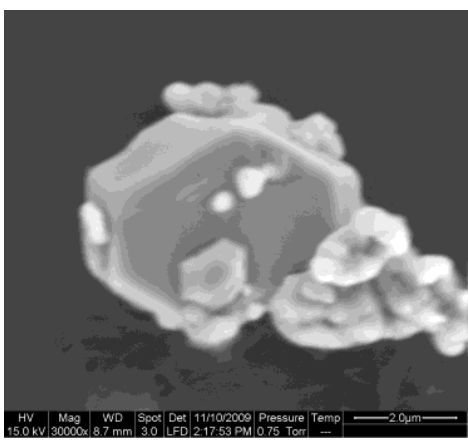

(c)

Figure 6. Scanning electron microscope photograph of attapulgite with added dispersant agents (a: attapulgite rods with STPP; b: upper attapulgite dispersion with added CPAM; c: lower attapulgite dispersion with added CPAM)

STPP means sodium tripolyphosphate; CPAM means cationic polyacrylamide.

Effects of Chemical Additives on YP/PV. As was said above, a basic optimal value range of YP/PV was $0.25-3.00$ according to API requirement. The YP/PV of untreated attapulgite was too 
high. Experimental measurements of YP/PV (Fig. 7) revealed a significant decrease with increasing dosage of $\mathrm{MgO}$.

The study in this paper aimed to find a new gel through modification, to get close to the rheological parameters of asbestos and so finally replace asbestos altogether. So $\mathrm{MgO}$ was chosen as a good modifying agent.

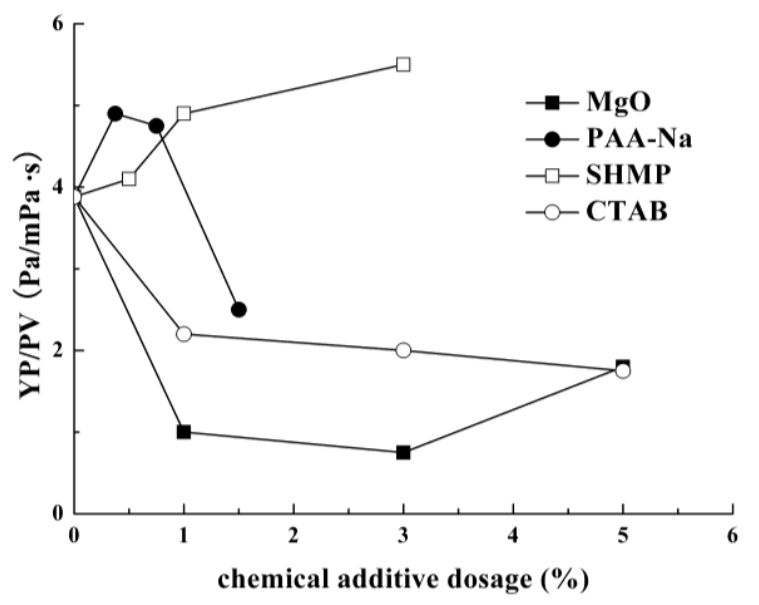

Figure 7. Effect of chemical additives on the mass ratio of yield point(YP) to plastic viscosity (PV) of attapulgite gel in drilling fluid suspension

PAA-Na means sodium polyacrylate; SHMP means sodium hexametaphosphate; CTAB means hexadecyl trimethyl ammonium bromide; Units of $\%$ here defined a $w t \%$, means the ratio of mass between chemicals and attapulgite

Effects of Chemical Additives on Gel Strength and Thixotropy. As non-Newtonian fluid, the thixotropy of dispersions of clay mineral represent relationship between time and flowing property [15] thought that the low weight fraction of the rigid needle-like clay mineral was sensitive to the applied quiescent stress so that the needles oriented significantly in flow direction under shear force. With increased shear force, the flow property improved. The recovery of the structure of a drilling fluid increases viscosity when shear stops. Gel strength $(\tau)$ and $\Delta \tau$ are significant measurements to understand the structure of the recovered gel and its thixotropy. As stated above, the relationship between thixotropy of a fluid and the cutting suspension and circulation resistance of pump restart is of great practical importance.

Liu and Guo [23] prepared PAM-attapulgite. The attapulgite nanofibrils grafted to the water-soluble polyacrylamide had the much better dispersibility in water than the bare attapulgite nanofibrils, and the dispersion of the PAM-attapulgite nanofibrils also had better stability.

Experimental measurements of gel strength and $\Delta \tau$ (Fig. 8) revealed that the effect of CPAM on the decreasing rate of $\tau$ and $\Delta \tau$ was more obvious. In addition, the final $\tau$ of the attapulgite gel modified with CPAM was not too large or too small when compared with other additives.

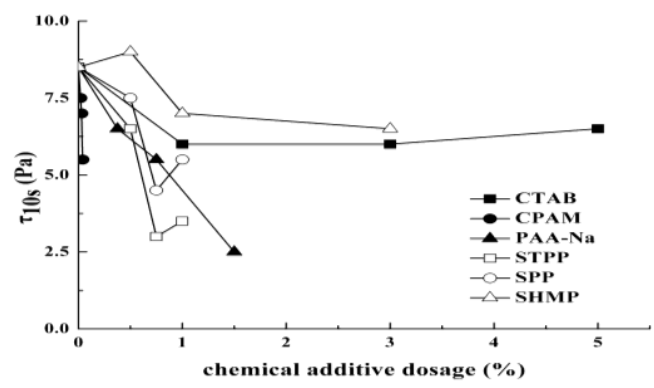

(a)

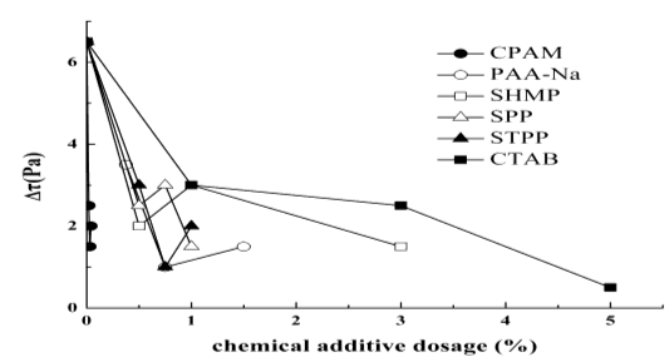

(b)

Figure 8. Effect of chemical additives on gel strength $\left(\tau_{10 \mathrm{~s}}\right)(\mathrm{a})$ and $\Delta \tau(\mathrm{b})$ of attapulgite gel in drilling fluid suspension. 
PAA-Na means sodium polyacrylate; STPP means sodium tripolyphosphate; SPP means sodium pyrophosphate; SHMP means sodium hexametaphosphate; CTAB means hexadecyl trimethyl ammonium bromide; CPAM means cationic polyacrylamide. Units of $\%$ here defined a wt $\%$, means the ratio of mass between chemicals and attapulgite.

The CTAB, CPAM, PAA-Na, SPP, STPP, and SHMP used in this study were regarded as dispersants. The mechanism of the dispersants on the dispersion was mainly through electrostatic repulsion and steric hindering. The reason of former was owing to reverse charges brought by the clay mineral rod surfaces absorbing dispersant. The reason of latter was the thickness and sliding of macromolecular repulsion. Gungor [24] investigated the effect of the adsorption of surfactants on the rheology of Na-bentonite dispersion. With cationic polymers, adsorption on negative-charged surfaces and consequent flocculation occurred by electrostatic attraction. With anionic polymers, the hydrogen bonding between the solid surfaces and hydroxyl groups on the polymer resulted in the adsorption and flocculation. Shen et al. [25] pre-modified attapulgite with CTAB; the Fourier-transform infrared (FTIR) spectroscopy results reflected the success of this organic modification.

The dispersed state of attapulgite adding dispersants revealed that the recovery and strength of the configuration (network structure) was slow and weak. The SEM measurements of attapulgite modified by CPAM (Fig. 9) showed that, compared to bare attapulgite, the stacking and clusters of attapulgite modified by CPAM were rapidly reduced. The dispersed rods were fibrous or needle-like. For CPAM, the cationic neutralized part of the clay mineral's negative charges and caused aggregates or repulsion to break up the configuration between the attapulgite rods. On the other hand, by an ion-exchange process with the attapulgite, absorbed long carbon-chain polymers of CPAM crossed when shear stopped. The softness of the chains bridging structure ensured gel strength and fast and weak thixotropy. Hamed and Belhadri [26] added biopolymers to adjust the rheological properties of drilling fluids and then the polymer molecules interacted with each other to form a complex network.

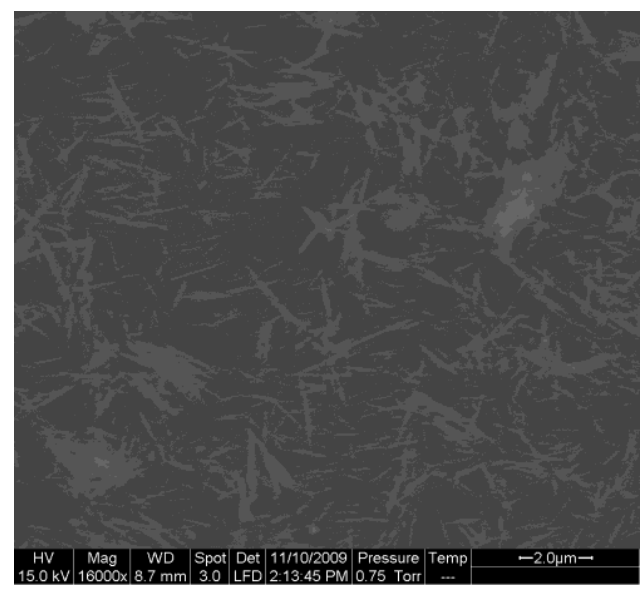

Figure 9. Scanning electron microscope photograph of attapulgite modified by cationic polyacrylamide (CPAM)

Effects of Chemical Additives on the Filtrate Loss of Gel. Alpha sodium naphthol sulfonate (FDN) was a kind of anionic surfactant, which when added to a gel, improves anion absorption to attapulgite particles. Like dispersant, drilling fluid suspension in the gel with added FDN is well dispersed and stable with the process of filtration, well dispersed particles developed into a thin and dense caked mud, with resultant low filtrate loss (FL). Experimental measurement of filtrate loss of gel (Fig. 10) showed that filtrate loss of gel with dispersants declined and FDN was more effective. 


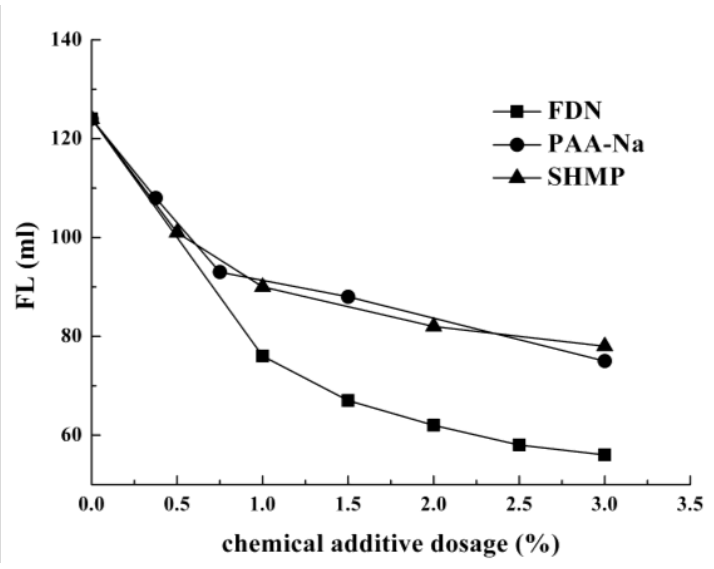

Figure 10. Effect of chemical additives on the filter loss (FL) of attapulgite gel in drilling fluid suspension.

FDN means alpha sodium naphthol sulfonate; PAA-Na means sodium polyacrylate; SHMP means sodium hexametaphosphate; Units of $\%$ here defined a $w t \%$, means the ratio of mass between chemicals and attapulgite.

The effects of chemical additives on the rheology and thixotropy of attapulgite gel were examined through a single-factor experiment and the optimal additives were MgO, PAA-Na, CPAM, and FDN. The optimized dosages of MgO, PAA-Na, FDN, and CPAM were 3\%, 1.5\%, 2.5\% and $0.04 \%$, respectively. The orthogonal test (Table 2 ) was designed according to the optimized dosages of four chemicals.

Table $2 \quad \mathrm{~L}_{9}\left(3^{4}\right)$ orthogonal test schedule

\begin{tabular}{ccccc}
\hline \multirow{2}{*}{ Levels } & \multicolumn{4}{c}{ Factors $(w t \%)$} \\
\cline { 2 - 5 } & $\mathrm{A}(\mathrm{MgO})$ & $\mathrm{B}(\mathrm{PAA}-\mathrm{Na})$ & $\mathrm{C}(\mathrm{FDN})$ & $\mathrm{D}(\mathrm{CPAM})$ \\
\hline Level 1 & 2.5 & 0.50 & 0.5 & 0.03 \\
Level 2 & 3.0 & 0.75 & 1.0 & 0.04 \\
Level 3 & 3.5 & 1.00 & 1.5 & 0.05 \\
\hline
\end{tabular}

PAA-Na means sodium polyacrylate; FDN means alpha sodium naphthol sulfonate; CPAM means cationic polyacrylamide. Units of $\%$ here defined as a $w t \%$, means the ratio of mass between chemicals and attapulgite.

The optimized conditions for the orthogonal design were $3.5 \% \mathrm{MgO}, 0.75 \%$ PAA-Na, $0.5 \%$ FDN, $0.05 \%$ CPAM, producing a modified attapulgite (Sample No.8).

Experimental measurement of thixotropy of gels (Table 3) revealed that the rheological and thixotropic parameters of the modified gel i.e. Sample No.8 were close to those of asbestos. The $\tau$ and $\Delta \tau$ declined noticeably. Thus, the Sample No.8 could be substituted for asbestos as a thixotropic modifier of drilling fluids.

Table 3 The contrast in thixotropic properties between attapulgite, asbestos gel and the Sample No.8 gel

\begin{tabular}{lcccccccc}
\hline \multicolumn{1}{c}{ Clay } & AV & PV & YP & $\tau_{10 \mathrm{~s}}$ & $\tau_{10 \min }$ & $\Delta \tau$ & YP/PV & FL \\
\hline Attapulgite & 19.5 & 4 & 15.5 & 8.5 & 15 & 6.5 & 3.88 & 124 \\
Asbestos & 17.5 & 14 & 3.5 & 3 & 2.5 & -0.5 & 0.25 & 32 \\
Sample No.8 & 15.5 & 14 & 1.5 & 5 & 5.5 & 0.5 & 0.11 & 58 \\
\hline
\end{tabular}




\section{Conclusions}

The modified attapulgite gel as a rheological modifier in drilling fluid suspension was obtained by adding chemical additives such as dispersants and aggregated agents. The different additives had different effects on the rheological behavior of attapulgite gel.

Magnesium oxide showed a great contribution to apparent viscosity and plastic viscosity of attapulgite aqueous suspensions because of the electrostatic attractive interactions between magnesium oxide particles and attapulgite rods. The interactions adjusted the electrolyte level of the dispersions, influenced the surface charge of the clay mineral particles, broken up the aggregated configuration of attapulgite gel, and then improved the yield point of the attapulgite suspension. This higher viscosity will provide a better cuttings carrying capability during drilling fluid circulation especial at low velocity.

The yield point was declined with increasing dosage of dispersants in present work. PAA-Na revealed a superior effect to other dispersants for the rheological behavior of attapulgite gel. In drilling applications, keeping YP at an appropriate level was critical to avoid a washing wall and doing harm to the stability of the borehole.

CPAM was an effective additive which affected the gel strength and the gel structure shift on time-dependent at low content. The optimized rheological modifier was obtained in present work which contained $3.5 \% \mathrm{MgO}, 0.75 \%$ PAA-Na, $0.5 \% \mathrm{FDN}$, and $0.05 \% \mathrm{CPAM}$ in the attapulgite clay.

The present work provided a practical way to prepare modified attapulgite gel to substitute asbestos in drilling fluid applications especially as a rheological control agent. The thixotropic parameters of the attapulgite gel were close to that of asbestos powder in water-based drilling fluid. Attapulgite gel could effectively substitute harmful asbestos and to some degree provided a better occupational safe protection.

\section{Conflict of Interests}

The authors declare that there is no conflict of interests regarding the publication of this paper.

\section{Acknowledgements}

Thanks Dr Susan Turner (Brisbane) for helpful comments the manuscript and improves on English. And we also thanks for this research work was supported by The National Key Technology R\&D Program of China (2014BAC31B01).

\section{References}

[1] H.C.H.Darley and R.G.George, Composition and properties of drilling and completion fluids. Gulf Professional Publishing Company, Houston, TX, Chapter 3, 92 -104, 1988.

[2] OGP/IPIECA Health Committee by the Drilling Fluids Task Force, Drilling fluids and health risk management--A guide for drilling personnel, managers and health professionals in the oil and gas industry, OGP Report Number 396, International Petroleum Industry Environmental Conservation Association(IPIECA) and International Association of Oil \& Gas Producers(OGP), 2009

[3] N.Alexander and S.Arieh, "Possible use of the Sacalum (Yucatan) palygorskite as drilling muds", Applied Clay Science, vol.25, no.1-2, pp.121-124, 2004.

[4] Chen, T. H, "Nanometer scale mineralogy and geochemistry of palygorskite clays in the border of Jiangsu and Anhui provinces", PhD thesis of Hefei University of Technology, 2003.

[5] Q.H.Fan, D.D.Shao, J.Hu, W.S.Wu, and X.K.Wang, "Comparison of $\mathrm{Ni}^{2+}$ sorption to bare and ACT-graft attapulgites: Effect of $\mathrm{pH}$, temperature and foreign ions", Surface Science, vol.602, 
no.3, pp.778-785, 2008.

[6] J.Zhang, S.D.Xie, and Y.S.Ho, "Removal of fluoride ions from aqueous solution using modified attapulgite as adsorbent", Journal of Hazardous Materials, vol.165, no.1, pp.218-222, 2009.

[7] V. Mahto and V.P. Sharma, "Rheological study of a water based oil well drilling fluid",Journal of Petroleum Science and Engineering, vol.45, no.1, pp.123-128,2004.

[8] J.D.G.Dur'an, M.M.Ramos-Tejada, F.J.Arroyo, and F.Gonz'alez-Caballero, 'Rheological and electrokinetic properties of sodium montmorillonite suspensions I. Rheological properties and interparticle energy of interaction", Journal of Colloid and Interface Science, vol.229, no.1, pp.107-117, 2000.

[9] S.H.Change, M.E.Ryan, and R.K.Gupta, "The effect of $\mathrm{pH}$, ionic strength, and temperature on the rheology and stability of aqueous clay suspensions", Rheologica Acta, vol.32, no.3, pp.263-269,1993.

[10] ANSI/API Recommended Practice 13B-1, "Recommended Practice for field testing water-based drilling fluids", 4th edition, American Petroleum Institute, Dallas, TX, March 2009.

[11]ANSI/API Specification 13A, "Specification for Drilling Fluids Materials",18th edition, American Petroleum Institute(API), Dallas, TX, February 2010.

[12] Falode, O.A.Ehinola, and P.C. Nebeife, "Evaluation of local bentonitic clay as oil well drilling fluids in Nigeria", Applied Clay Science, vol.39, no.1 pp.19-27, 2008.

[13] V.C.Kelessidis, C.Tsamantaki, and P.Dalamarinis, "Effect of $\mathrm{pH}$ and electrolyte on the rheology of aqueous Wyoming bentonite dispersions", Applied Clay Science, vol.38, no.1,pp.86-96, 2007.

[14] P.F.Luckham and S.Rossi,"The colloidal and rheological properties of bentonite suspensions", Advances in Colloid and Interface Science,vol.82, no.1, pp.43-92,1999.

[15]H.Yin, D.Mo and D.J. Chen, "Orientation behavior of attapulgite nanoparticles in poly(acrylonitrile)/attapulgite solutions by rheological analysis", Journal of Polymer Science: Part B: Polymer Physics, vol.47, no.10, pp.945-954, 2009.

[16] J.Zhou, N.Liu,Y.Li, and Y.J. Ma, "Microscopic Structure Characteristics of attapulgite", Bulletin of the Chinese Ceramic Society, no.6, pp.50-55, 1999.

[17] J.Zhou, L.J.Liu, N.Liu, and X.F. Liu, "Effects of $\mathrm{Mg}(\mathrm{OH})_{2}$ and $\mathrm{MgO}$ on rheological behavior of attapulgite clay-water suspensions", Journal of Hefei University of Technology, vol.22, no.6, pp.58-63,1999.

[18]E.H.Cao, R.Bryant, and D.J.A.Williams, "Electrochemical properties of Na-attapulgite", Journal of Colloid and Interface Science, vol.179, no.1, pp.143-150,1996.

[19]Z.W.Zhou, P.J.Scales, and D.V.Boger, "Chemical and physical control of the rheology of concentrated metal oxide suspensions", Chemical Engineering Science, vol.56, no.9, pp.2901-2920, 2001.

[20]E.B.Kristen and A.M.Jonas, "Interfacial-chemistry mediated behavior of colloidal talc dispersions", Journal of Colloid and Interface Science, vol.283, no.2, pp.385- 391, 2005.

[21] Y.L.Jin,J.Chen,Y.H.Qian, H.Q.Yao, and W.Li, "Choice of pure dispersant for preparing ultrafine and pure attapulgite", China Mining Magazine, vol.14, no.1, pp.76-78, 2005.

[22] P.S.Monkton, D.P.Sparks, and D.R.Cockeysville, "Purified attapulgite clay", United States Patent 6130179, issued October 10, 2000.

[23] P.Liu and J.S.Guo,"Polyacrylamide grafted attapulgite (PAM-ATP) via surface-initiated atom transfer radical polymerization (SI-ATRP) for removal of $\mathrm{Hg}$ (II) ion and dyes", Colloids and Surfaces A: Physicochemical and Engineering Aspects, vol.283, pp.498-503, 2006.

[24] N.Gungor, "Effect of the adsorption of surfactants on the rheology of Na-bentonite slurries", Journal of Applied Polymer Science, vol.75, no.1, pp.107-110, 2000.

[25] L.Shen, Y.J.Lin, Q.G. Du, W.Zhong, and Y.L.Yang, "Preparation and rheology of polyamide-6/attapulgitenanocomposites and studies on their percolated structure",Polymer, vol.46, no.15, pp.5758-5766, 2005.

[26] S.B.Hamed and M.Belhadri, "Rheological properties of biopolymers drilling fluids",Journal of Petroleum Science and Engineering, vol.67, no.3, pp.84-90, 2009. 